\title{
Dynamical Analysis of the Mechanical System with Two Degrees of Freedom Applied to the Transmission of the Wind Turbine
}

\author{
Maria Luminița Scutaru ${ }^{1}$ and Bogdan Mitrica ${ }^{2}$ \\ ${ }^{1}$ Department of Mechanical Engineering, Transilvania University of Brasov, 29 Eroilor Boulevard, 500036 Brasov, Romania \\ ${ }^{2}$ Horia Hulubei National Institute for R\&D in Physics and Nuclear Engineering (IFIN-HH), Romania
}

Correspondence should be addressed to Bogdan Mitrica; mitrica@nipne.ro

Received 19 January 2016; Accepted 8 March 2016

Academic Editor: Giovanni Garcea

Copyright (C) 2016 M. L. Scutaru and B. Mitrica. This is an open access article distributed under the Creative Commons Attribution License, which permits unrestricted use, distribution, and reproduction in any medium, provided the original work is properly cited.

\begin{abstract}
The authors develop a mathematical model to analyze the transmission of wind-driven water pumps in order to determine their dynamic response, stability, and stresses occurring in the transmission elements. The authors propose, as an innovative solution, the use of a mechanism with two degrees of freedom that provides automatically a flexibility of the transmission ratio and the harmonization of the turbine operation with the wind velocity. To verify the results a stand was carried out as physical mechanism on which measurements and recordings of the significant mechanical parameters of the system are made.
\end{abstract}

\section{Introduction}

There are many practical solutions for mechanical transmissions using wind turbine pumps (some more used solutions, mostly in agricultural farms and in individual activities [17]). However the progress made by the revolution of the new materials with superior properties and the possibility of making careful calculations of the transmission make new solutions possible and desirable showing wind turbine pumps, reliable, easy to maintain and install, and with a low price of manufacturing (the possibilities of new solutions are presented in [8-12]). To eliminate the inconvenience of a mechanism with constant transmission ratio (hard starting to small wind and overspeed to strong) a mechanism is proposed with automatic variable transmission ratio depending on input conditions (wind speed).

To make an analysis of such system a mathematical model is performed and the motion equations are obtained. Mixed system of differential equations, where algebraic and differential unknowns occur (DAE: differential algebraic equations), will be reduced to a system of second-order differential equations (ODE: ordinary differential equations).
Numerical integration of the equations of motion was made and it is possible to compute, with linear relations, the liaison forces. The equations obtained, using the classical methods, are a differential system of second order where, near the unknowns independent coordinates, the unknowns liaison forces are in linear combinations. If we consider the different nature of these two kinds of unknowns some problems result when we want to solve the equations. The usual way is to eliminate, in the first step, the liaison forces and, in the second step, to solve the differential equations system. The time evolution of the independent coordinates is known to determine the liaison forces return to solve a linear system. The theoretical conclusions were validated using an experimental stand.

\section{Dynamic Analysis of the Transmission with Two Degrees of Freedom}

The originality of the proposed mechanism (Figure 1) is to use the inertia of one of its elements and continuously change gear ratio as the input speed increases ([13-17]). 


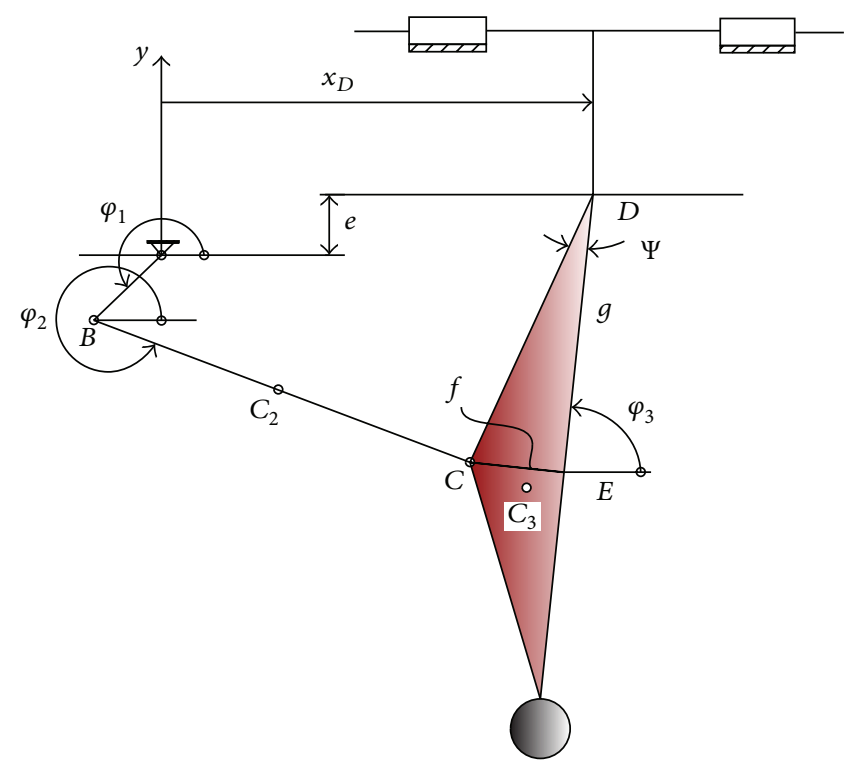

FIgURE 1: Mechanism with two degrees of freedom.

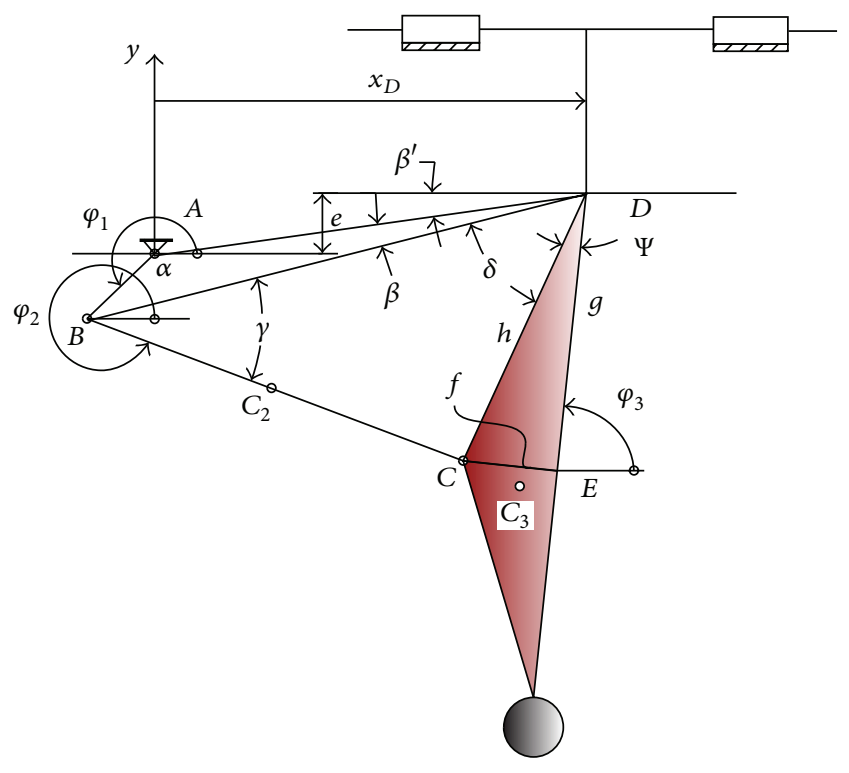

FIGURE 2: Geometry of the mechanism.

In this respect, the mechanism will have two degrees of freedom, which could be considered the input rotation angle (crank $A B$ ) and the pump stroke (coordinate of the point $D$ ), denoted by $x_{D}$ (Figure 2).

Geometry of the mechanism makes it possible to write the closing vector equations (Figure 3 ):

$$
\begin{array}{r}
l_{1} c_{1}+l_{2} c_{2}+h c_{3-\psi}-x_{D}=0, \\
l_{1} s_{1}+l_{2} s_{2}+h s_{3-\psi}-e=0,
\end{array}
$$

where $h=\sqrt{f^{2}+g^{2}}, c_{1}=\cos \varphi_{1}, c_{2}=\cos \varphi_{2}, c_{3-\psi}=\cos \left(\varphi_{1}-\right.$ $\psi), s_{1}=\sin \varphi_{1}, s_{2}=\sin \varphi_{2}$, and $s_{3-\psi}=\sin \left(\varphi_{3}-\psi\right)$, the other notations being indicated in Figure 2.

Using the closing vector equations is possible to obtain the values of angles $\varphi_{2}$ and $\varphi_{3}$ depending on the angle $\varphi_{1}$ and the displacement $x_{D}$.

By differentiating (1), condition equations for velocities are obtained:

$$
\begin{aligned}
-l_{1} \omega_{1} s_{1}-l_{2} \omega_{2} s_{2}-h \omega_{3} s_{3-\psi}-\dot{x}_{D} & =0, \\
l_{1} \omega_{1} c_{1}+l_{2} \omega_{2} c_{2}+h \omega_{3} c_{3-\psi} & =0 .
\end{aligned}
$$

We can write

$$
\left\{\begin{array}{l}
l_{2} \omega_{2} \\
h \omega_{3}
\end{array}\right\}=\left[\begin{array}{ll}
a_{11} & a_{12} \\
a_{21} & a_{22}
\end{array}\right]\left\{\begin{array}{c}
l_{1} \omega_{1} \\
\dot{x}_{D}
\end{array}\right\}
$$

where the notations for $a_{11}, a_{12}, a_{21}$, and $a_{22}$ are presented in [18].

The condition equations for accelerations can be obtained differentiating (2),

$$
\begin{aligned}
& -l_{1} \varepsilon_{1} s_{1}-l_{2} \varepsilon_{2} s_{2}-h \varepsilon_{3} s_{3-\psi}-l_{1} \omega_{1}^{2} c_{1}-l_{2} \omega_{2}^{2} c_{2}-h \omega_{3}^{2} c_{3-\psi} \\
& \quad-\ddot{x}_{D}=0 \\
& l_{1} \varepsilon_{1} c_{1}+l_{2} \varepsilon_{2} c_{2}+h \varepsilon_{3} c_{3-\psi}-l_{1} \omega_{1}^{2} s_{1}-l_{2} \omega_{2}^{2} s_{2} \\
& -h \omega_{3}^{2} s_{3-\psi}=0
\end{aligned}
$$




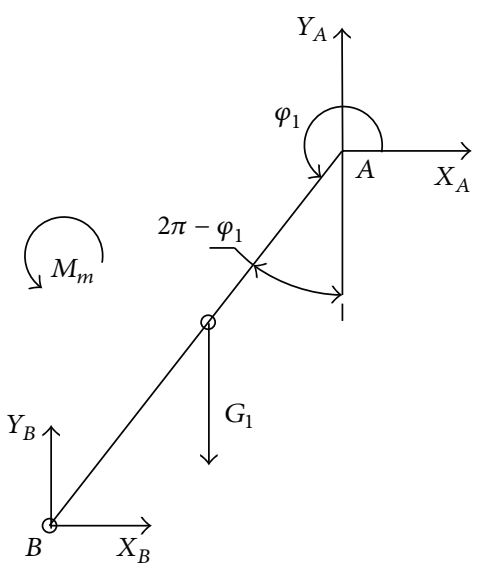

(a)

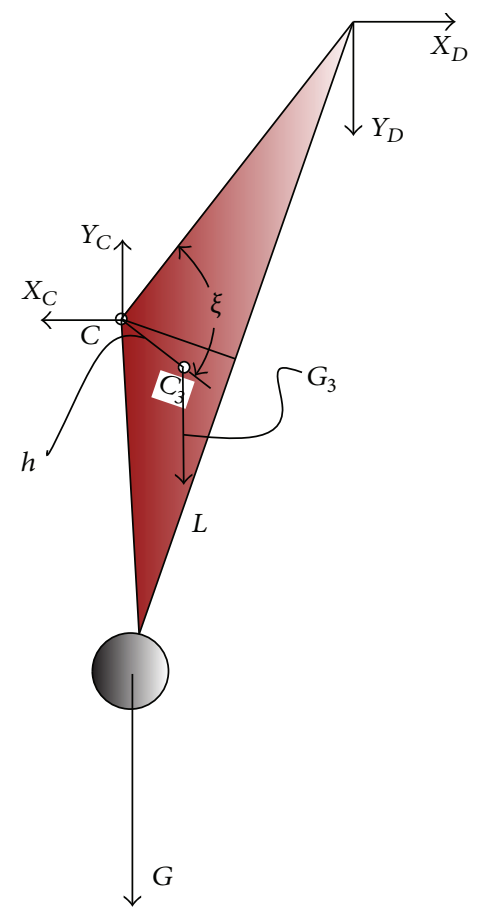

(c)

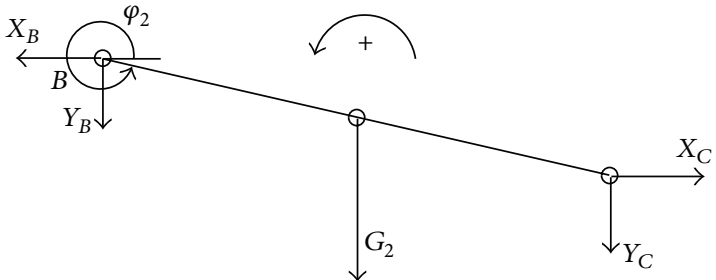

(b)

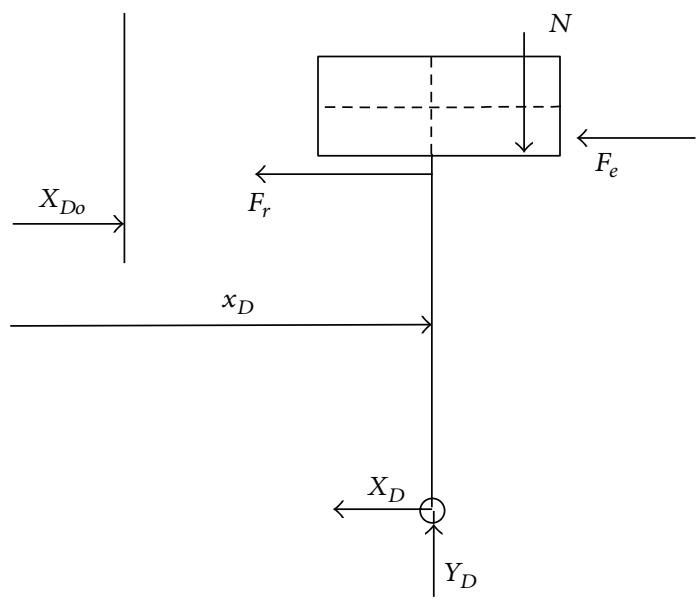

(d)

FIGURE 3: Free body diagram of the bodies of the system.

from where the angular accelerations can be obtained as

$$
\begin{aligned}
\left\{\begin{array}{l}
l_{2} \varepsilon_{2} \\
h \varepsilon_{3}
\end{array}\right\}= & {\left[\begin{array}{ll}
a_{11} & a_{12} \\
a_{21} & a_{22}
\end{array}\right]\left\{\begin{array}{l}
l_{1} \varepsilon_{1} \\
\ddot{x}_{D}
\end{array}\right\} } \\
& +\left[\begin{array}{lll}
b_{11} & b_{12} & b_{13} \\
b_{21} & b_{22} & b_{23}
\end{array}\right]\left\{\begin{array}{l}
\left(l_{1} \omega_{1}\right)^{2} \\
l_{1} \omega_{1} \dot{x}_{D} \\
\left(\dot{x}_{D}\right)^{2}
\end{array}\right\},
\end{aligned}
$$

where the notations for $b_{11}, b_{12}, b_{13}, b_{21}, b_{22}$, and $b_{23}$ are presented in [18].
The mass center positions are obtained using the following relations:

$$
\begin{aligned}
& x_{1}=a_{1} l_{1} c_{1} ; \\
& y_{1}=a_{1} l_{1} s_{1}, \\
& x_{2}=l_{1} c_{1}+a_{2} l_{2} c_{2} ; \\
& y_{2}=l_{1} s_{1}+a_{2} l_{2} s_{2}, \\
& x_{3}=l_{1} c_{1}+l_{2} c_{2}+h g \cdot c_{3-\psi-\xi} ; \\
& y_{3}=l_{1} s_{1}+l_{2} s_{2}+h g \cdot s_{3-\psi-\xi},
\end{aligned}
$$


from which it is possible to obtain the vector of accelerations:

$$
\{a\}=\left[\begin{array}{llllllllll}
\ddot{x}_{1} & \ddot{y}_{1} & \varepsilon_{1} & \ddot{x}_{2} & \ddot{y}_{2} & \varepsilon_{2} & \ddot{x}_{3} & \ddot{y}_{3} & \varepsilon_{3} & \ddot{x}_{D}
\end{array}\right]^{T}
$$

by differentiation. Finally the accelerations vector under the following form can be written:

$$
\begin{aligned}
&\{a\}= {\left[\left\{A_{1}\right\}\left\{A_{2}\right\}\right]\left\{\begin{array}{c}
\varepsilon_{1} \\
\ddot{x}_{D}
\end{array}\right\} } \\
&+\left[\left\{B_{1}\right\}\left\{B_{2}\right\}\left\{B_{3}\right\}\right]\left\{\begin{array}{c}
\left(\omega_{1}\right)^{2} \\
\left(\omega_{1} \dot{x}_{D}\right) \\
\left(\dot{x}_{D}\right)^{2}
\end{array}\right\} \\
&=[A]\left\{\begin{array}{c}
\varepsilon_{1} \\
\ddot{x}_{D}
\end{array}\right\}+[B]\left\{\begin{array}{c}
\left(\omega_{1}\right)^{2} \\
\left(\omega_{1} \dot{x}_{D}\right) \\
\left(\dot{x}_{D}\right)^{2}
\end{array}\right\},
\end{aligned}
$$

where the notations for the matrixes $\left\{A_{1}\right\},\left\{A_{2}\right\},\left\{B_{1}\right\},\left\{B_{2}\right\}$, $\left\{B_{3}\right\},[A]=\left[\left\{A_{1}\right\}\left\{A_{2}\right\}\right]$, and $[B]=\left[\left\{B_{1}\right\}\left\{B_{2}\right\}\left\{B_{3}\right\}\right]$ are obvious. The motion equations can be written in a compact form (view [19-21]):

$$
[m]\{a\}=\{Q\}
$$

If in rel. (8) the vector of the accelerations (7) is used, it results in

$$
\begin{aligned}
& {[m]\left([ \{ A _ { 1 } \} \{ A _ { 2 } \} ] \left\{\begin{array}{c}
\varepsilon_{1} \\
\left.\ddot{x}_{D}\right\}
\end{array}\right.\right.} \\
& \left.+\left[\left\{B_{1}\right\}\left\{B_{2}\right\}\left\{B_{3}\right\}\right]\left\{\begin{array}{c}
\omega_{1}^{2} \\
\omega_{1} \dot{x}_{D} \\
\dot{x}_{D}^{2}
\end{array}\right\}\right)=\{Q\} .
\end{aligned}
$$

$$
\begin{aligned}
& \left\{\begin{array}{c}
\varepsilon_{1} \\
\ddot{x}_{D}
\end{array}\right\}=\{\dot{Y}\}
\end{aligned}
$$

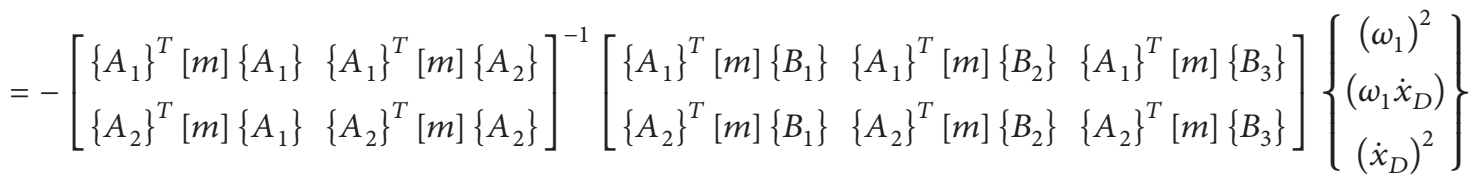

$$
\begin{aligned}
& +\left[\begin{array}{ll}
\left\{A_{1}\right\}^{T}[m]\left\{A_{1}\right\} & \left\{A_{1}\right\}^{T}[m]\left\{A_{2}\right\} \\
\left\{A_{2}\right\}^{T}[m]\left\{A_{1}\right\} & \left\{A_{2}\right\}^{T}[m]\left\{A_{2}\right\}
\end{array}\right]^{-1}\left[\begin{array}{c}
\left\{A_{1}\right\}^{T}\{Q\} \\
\left\{A_{2}\right\}^{T}\{Q\}
\end{array}\right] .
\end{aligned}
$$

To eliminate the liaison forces it must premultiply the rel. (9) (view [21-28]) with

$$
\left[\begin{array}{l}
\left\{A_{1}\right\}^{T} \\
\left\{A_{2}\right\}^{T}
\end{array}\right],
$$

and we obtain

$$
\begin{aligned}
& {\left[\begin{array}{c}
\left\{A_{1}\right\}^{T} \\
\left\{A_{2}\right\}^{T}
\end{array}\right][m]\left(\left[\left\{A_{1}\right\}\left\{A_{2}\right\}\right]\left\{\begin{array}{c}
\varepsilon_{1} \\
\dot{x}_{D}
\end{array}\right\}\right.} \\
& \left.+\left[\left\{B_{1}\right\}\left\{B_{2}\right\}\left\{B_{3}\right\}\right]\left\{\begin{array}{c}
\omega_{1}^{2} \\
\left.\omega_{1} \dot{x}_{D}\right\} \\
\dot{x}_{D}^{2}
\end{array}\right\}\right)=\left[\begin{array}{c}
\left\{A_{1}\right\}^{T} \\
\left\{A_{2}\right\}^{T}
\end{array}\right]\{Q\} .
\end{aligned}
$$

If calculus is made it results in

$$
\begin{aligned}
& {\left[\begin{array}{ll}
\left\{A_{1}\right\}^{T}[m]\left\{A_{1}\right\} & \left\{A_{1}\right\}^{T}[m]\left\{A_{2}\right\} \\
\left\{A_{2}\right\}^{T}[m]\left\{A_{1}\right\} & \left\{A_{2}\right\}^{T}[m]\left\{A_{2}\right\}
\end{array}\right]\left\{\begin{array}{c}
\varepsilon_{1} \\
\ddot{x}_{D}
\end{array}\right\}} \\
& +\left[\begin{array}{lll}
\left\{A_{1}\right\}^{T}[m]\left\{B_{1}\right\} & \left\{A_{1}\right\}^{T}[m]\left\{B_{2}\right\} & \left\{A_{1}\right\}^{T}[m]\left\{B_{3}\right\} \\
\left\{A_{2}\right\}^{T}[m]\left\{B_{1}\right\} & \left\{A_{2}\right\}^{T}[m]\left\{B_{2}\right\} & \left\{A_{2}\right\}^{T}[m]\left\{B_{3}\right\}
\end{array}\right]\left\{\begin{array}{c}
\omega_{1}^{2} \\
\omega_{1} \dot{x}_{D} \\
\dot{x}_{D}^{2}
\end{array}\right\}
\end{aligned}
$$

$$
=\left[\begin{array}{l}
\left\{A_{1}\right\}^{T}\{Q\} \\
\left\{A_{2}\right\}^{T}\{Q\}
\end{array}\right] .
$$

If we denote

$$
\begin{aligned}
& X=\left\{\begin{array}{l}
\varphi_{1} \\
x_{D}
\end{array}\right\} ; \\
& \dot{X}=Y,
\end{aligned}
$$

the nonlinear system of differential equations results:
The following integrations for some situations to check how the integration subroutines work will be performed (Figure 4). 


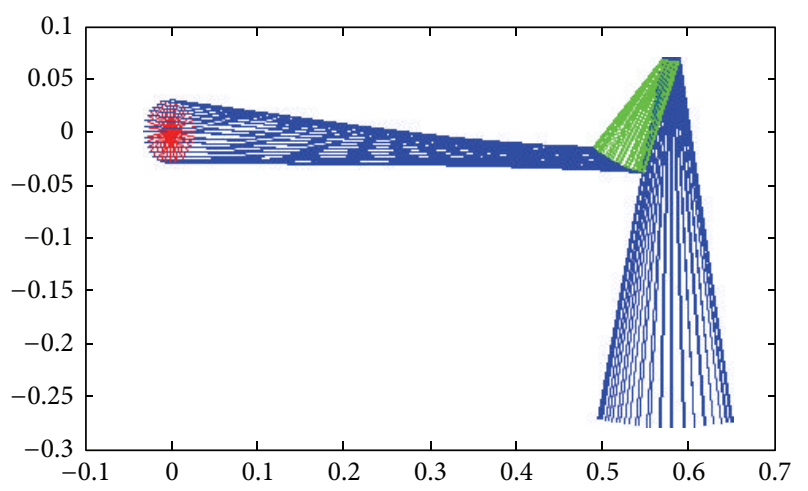

FIGURE 4: Sketch of the motion of the two degrees of freedom system for the angular speed $160 \mathrm{rot} / \mathrm{min}$.

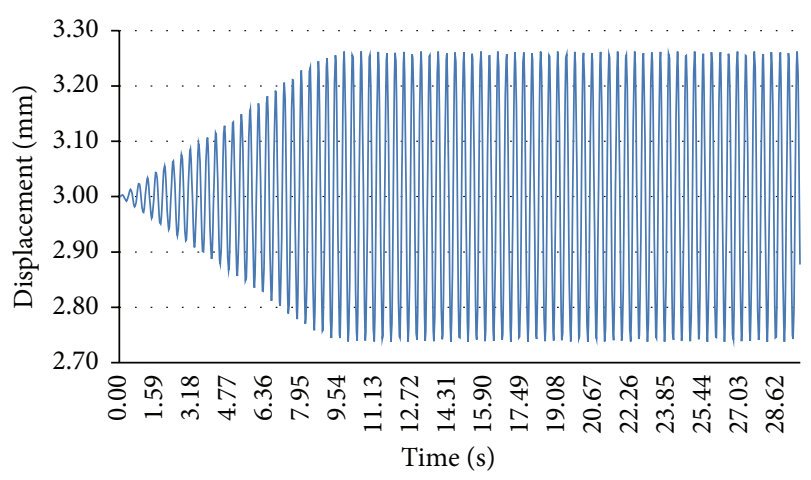

FIGURE 5: Slider displacement.

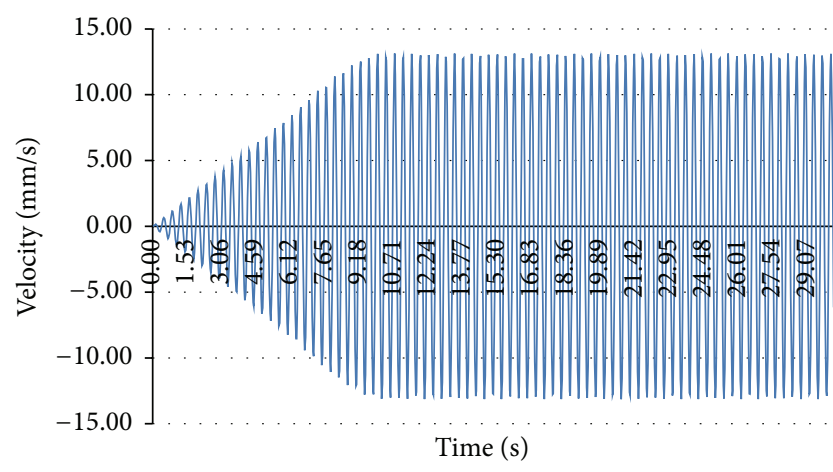

FIGURE 6: Slider velocity.

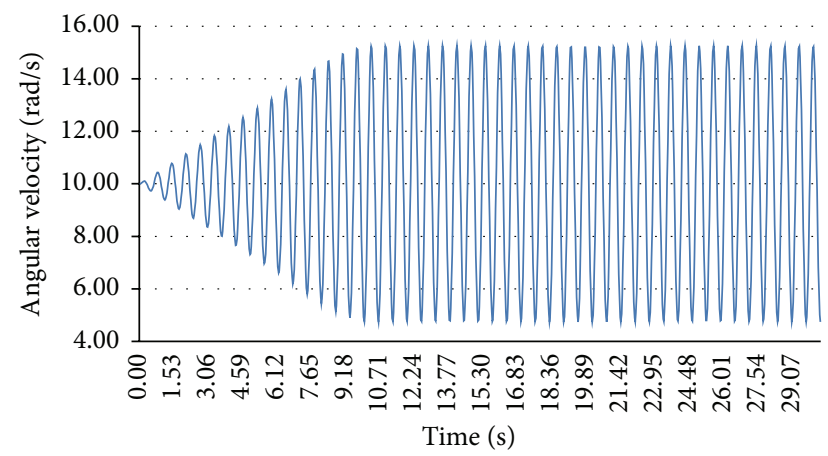

FIGURE 7: Angular velocity of the crank.

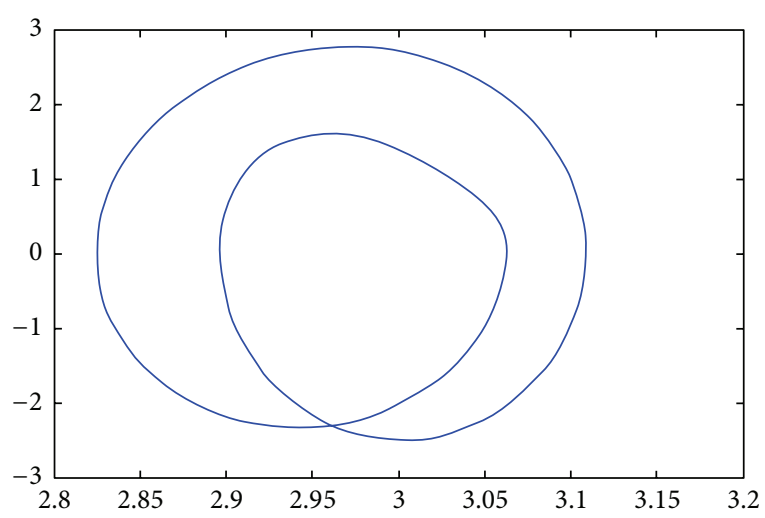

FIGURE 8: Slider motion representation in the phase space.

From Figures 5-8 it can be seen that there is a stable integration process for long intervals. The proposed system is a system with two degrees of freedom. As a result the system of DAE which is obtained when using the fundamental theorems of dynamics will be transformed, after removing the reactions, in a two second-order ODE. Integrating this system of equations can lead to numerical stability issues due to high complexity of the system.

We tried several subroutines integration of MATLAB programming environment and found that ode 23 subroutine has the best behavior. To study the stability of the integration process a quasi-stable operating regime has been sought and integration time became longer, to determine how long rounded errors lead to instability of the solution. For the latter presented final integration time of $200 \mathrm{~s}$ was chosen. This yields stable results.

\section{Experimental Confirmation of the Theoretical Results}

3.1. The Experimental Method Used in Measurements. In order to perform high-precision tests, also useful in verifying and validating accomplished models, we have used an optical recording method of the movement, which provides the opportunity for measurements under dynamic loading.

Dynamic analysis of the proposed mechanism allowed the numerical determination of the laws of motion of the elements of studied multibody system and the proposed experimental method will serve to validate these numerical results.

The current method based on motion analysis using a motion capture system is a particularly efficient and high perspective one. We have considered it appropriate to use the method with markers for the present research work. The equipment used is well suited for the records that we want to do as it can ensure shooting in dark surroundings with very good accuracy. In analyzing the motion with markers, the basic idea is to track the movement of a marker attached to a particular point of interest on the mechanism and then the trajectory of that point will be extracted and analyzed by methods that correspond to the desired outcome to be achieved. A motion capture software will therefore be able to 


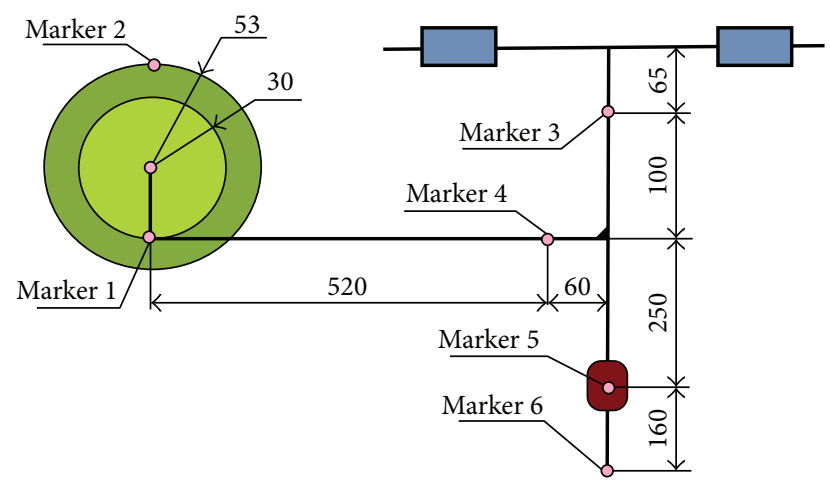

FIGURE 9: Sketch of the mechanism with markers highlighting.

follow the path of a marker over the entire motion and then to provide at least a list of coordinates of the marker over time, coordinates that define this trajectory.

In view of the above considerations, for the experimental research within this paper, the Adobe After Effects has been used, due to the following:

(i) Efficiency in terms of how motion is treated, the method of markers recognition, and accuracy with which the trajectory of a marker is recognized.

(ii) Accuracy in terms of tracking the trajectory according to several criteria (brightness, color intensity, etc.), but also influencing certain aspects of external conditions in which the capture is carried out (brightness, the distance at which the motion is captured).

(iii) The extent to which the results of the application are further processed to obtain the dimensions of the motion parameters that are analyzed in the thesis.

AOS [29] software allows saving shootings in common (.avi) video format being indispensable decreasing duration or their compression. This format has been used because of its compatibility with the application necessary to obtain experimental data.

3.2. Obtaining Experimental Data. After fulfilling the conditions for the experiment, the markers are fixed on mechanism after which the mechanism is recorded at different shooting modes, each mode (transformer-rectifier indication) being recorded on its own video. Markers will be centered on the main pump rod as well as on joints mechanism (Figure 9).

With Adobe After Effects application, the motion coordinates are retrieved for each marker. The same process will be covered for other markers of the video (pump marker and the pendulum marker) too. Thus, the data for the first recording have been obtained. The above steps are repeated for other records of the mechanism to finally get its corresponding database, followed by data processing.

The experimental setup allows testing the behavior of a mechanism with two degrees of freedom, "closed kinematic chain through inertia" (view [9]) for different engine speeds. The test program described previously allows experimental

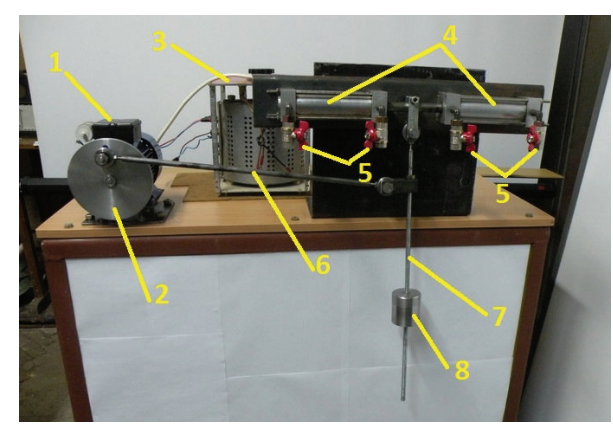

FIGURE 10: Experimental setup for testing. (1) Motor; (2) disc drive; (3) transformer; (4) pump; (5) valves; (6) rod; (7) pendulum rod; (8) weight.

tests and evaluation of certain kinematic parameters. The mechanism's components are shown in Figure 10.

3.3. Tests Achievement, Processing, and Interpretation of the Obtained Data. This section presents the results obtained from testing the mechanism with two degrees of freedom. The test represents the video recording of markers motion for three different load situations of piston pump. The research has been carried out in three different regimes and different valve positions.

In order to track, process, and evaluate the experimental data, the following notations have been made:

(i) movement with all valves open: all_o or 0_0_0_0;

(ii) movement with all extremity valves closed: C_o_O_c or 1_0_0_1;

(iii) movement with all valves closed: all-cl or 1_1_1_1.

Due to the fact that the used application (Adobe After Effects) has not been designed specifically for motion analysis, the trajectory tracking way is designed in order to apply the effect of motion on that path of some elements of video material, so this does not provide a direct possibility to export them in a known format. But markers coordinates ( $X$ and $Y$ ) can be copied in an Excel file that after some minor adjustments can be retrieved by other applications for further processing.

After the completion of the experimental tests, video recordings have been obtained representing the coordinates of the six markers corresponding to the four operating modes in the three loading cases (all_o, C_o_o_c, and all_c).

Mathematical processing of experimental data from videos has led to some results presented in graphical form.

The motion study of markers 1 and 2 is useful for determining the speed of the drive motor. Marker 3 will give the pistons motion and marker 5 allows determination of swinging motion (Figures 11-12).

The study of marker 5 motion has determined the following motion graphics (Figures 13-15).

The analysis in terms of marker 3 graphics led to the determination of the piston stroke. Similar is the case for all operating modes, in all established variants (all_o, C_o_o_c, and all_c), with the data being obtained from the centralized spreadsheet (Table 1) for plotting (Figures 16-18). 
TABLE 1

\begin{tabular}{|c|c|c|c|c|c|}
\hline \multicolumn{6}{|c|}{ Tap position } \\
\hline \multicolumn{2}{|c|}{ all_o } & \multicolumn{2}{|c|}{ C_O_O_C } & \multicolumn{2}{|c|}{ all_c } \\
\hline $\begin{array}{l}\text { Angular speed } \\
\text { (rot/min) }\end{array}$ & $\begin{array}{c}\text { Displacement } \\
(\mathrm{mm})\end{array}$ & $\begin{array}{c}\text { Angular speed } \\
(\mathrm{rot} / \mathrm{min})\end{array}$ & $\begin{array}{c}\text { Displacement } \\
(\mathrm{mm})\end{array}$ & $\begin{array}{c}\text { Angular speed } \\
(\text { rot } / \mathrm{min})\end{array}$ & $\begin{array}{c}\text { Displacement } \\
(\mathrm{mm})\end{array}$ \\
\hline 165.36 & 6.84 & 165.24 & 6.16 & 161.73 & 6.05 \\
\hline 183.15 & 9.58 & 176.93 & 8.74 & 163.71 & 8.04 \\
\hline 191.21 & 14.67 & 185.26 & 12.76 & 184.18 & 11.62 \\
\hline 197.11 & 15.86 & 192.56 & 15.30 & 191.67 & 15.04 \\
\hline
\end{tabular}

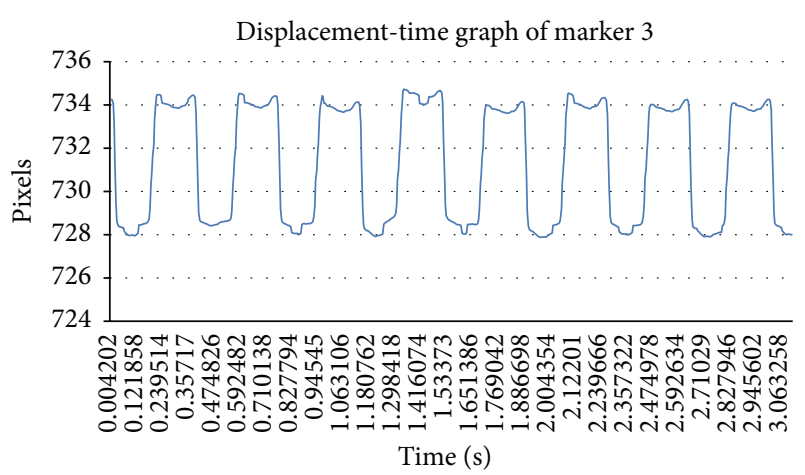

FIGURE 11: Horizontal displacement of marker 3.

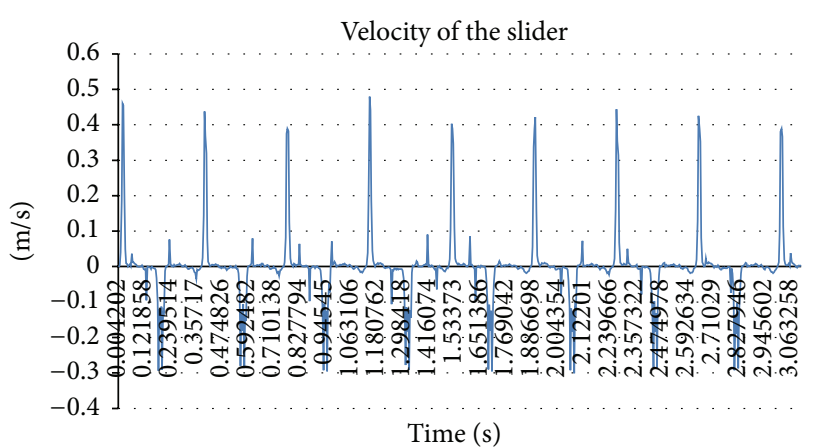

FIgURE 12: Horizontal speed of the slider.

The main advantage of studied mechanism with two degrees of freedom is in its transmission flexibility ratio. By this we mean that unlike the classical connecting rodcrank mechanism that has a constant transmission ratioindependently of the speed of the crank, the stroke is the same-the proposed two-degree-of-freedom mechanism is carried out at low speeds of the crank and a very low (or even zero) stroke, and as the frequency of rotation of the crank increases (i.e., wind speed increases), the stroke increases also, not only its frequency alternating motion.

Discontinuities in Figures 11-15 were largely due to errors in determining the exact position of the markers.

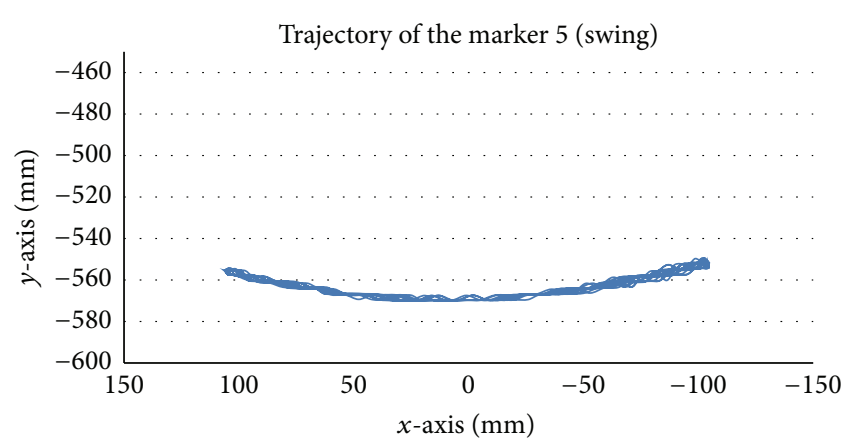

FIGURE 13: Path of marker 5.

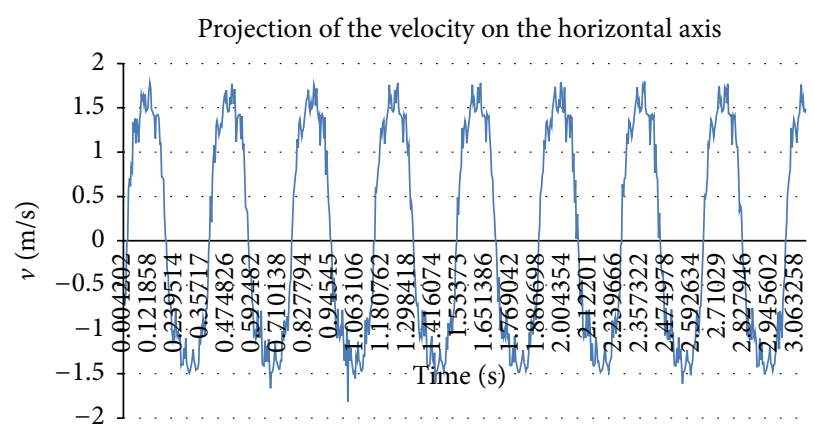

FIGURE 14: The projection of the speed on the horizontal axis of marker 5.

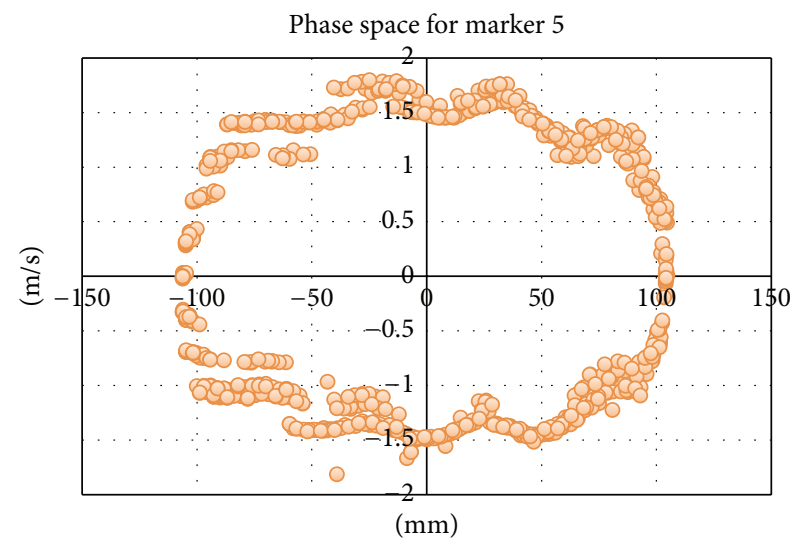

FIGURE 15: Phase space representation of displacement on the horizontal axis for marker 5 . 


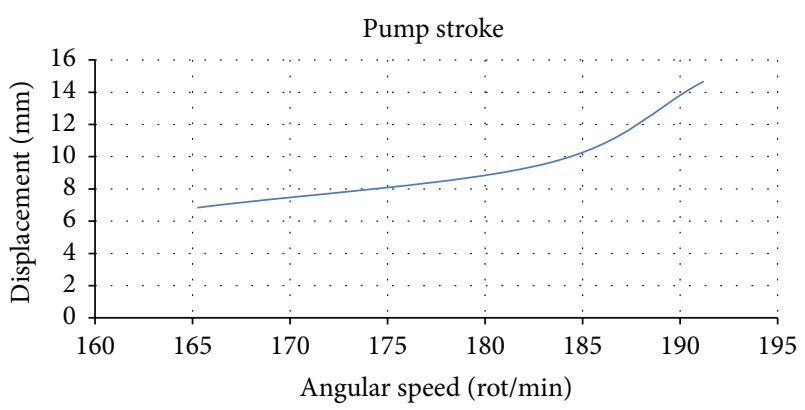

— Test 0_0_0_0

Figure 16: The displacement of the piston all_o.

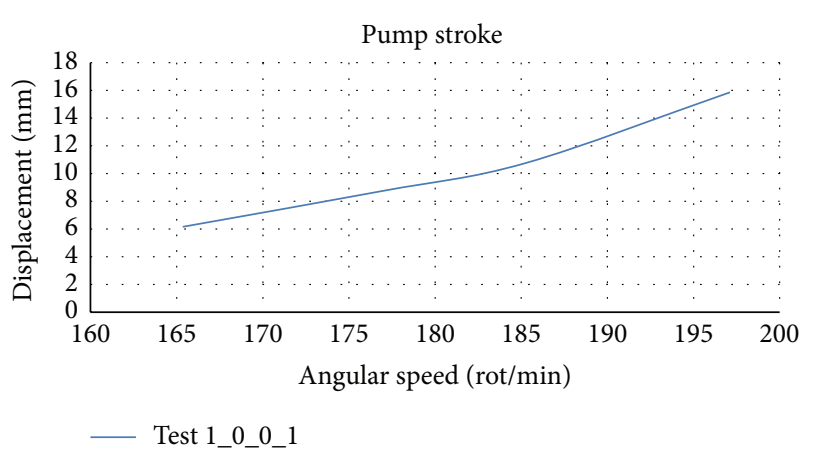

FIGURE 17: The displacement of the piston C_o_o_c.

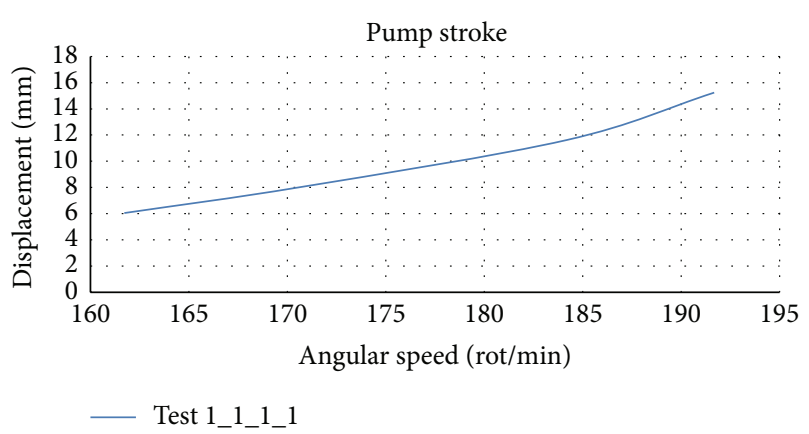

FIGURE 18: The displacement of the piston all_c.

\section{Conclusions}

Theoretical and experimental study carried out in paper have the aim to research the dynamic behavior of winddriven pumps, focusing on dynamic analysis of these pumps transmissions. A mechanism with two degrees of freedom to transmit and convert the rotation motion into translation one has been proposed. This type of mechanism has some structural advantages, one of which is that it can run the turbine at weak wind. At weak wind, the mechanism can function as a pendulum driven by turbine rotation, but as the turbine speed increases, the pendulum inertia moves the pump. This produces an increasing stroke of the piston, which increases the consumption of energy taken over by the pump and limits the turbine speed. The main advantage of mechanism with two degrees of freedom is studied in its transmission flexibility ratio. By this we mean that, unlike the classical connecting rod-crank mechanism that has a constant transmission ratio, in the sense that the piston stroke is the same, irrespective of the crank, the proposed mechanism of two degrees of freedom is carried out at very low (or even zero) stroke at low speeds of the crank, and as the frequency of rotation of the crank increases (i.e., wind speed increases) the stroke increases also, not only its frequency alternating motion.

This mechanism property provides the following benefits:

(i) Allowing startup of the vertical axis wind turbine at low wind speeds (thus avoiding the disadvantage of this type of wind turbines).

(ii) Accomplishing an increase of pump turbine efficiency with the increase of wind speed. This is obvious if you notice that as speed increases, both the number of racing pistons in unit time and the length of its stroke increase.

(iii) Limiting the speed in case of strong wind turbine, by substantially increasing the power consumed by the pump.

\section{Competing Interests}

The authors declare that they have no competing interests.

\section{Acknowledgments}

Bogdan Mitrica would like to thank the support of the Romanian National Authority for Scientific Research, ANCSUEFISCDI, under Grant no. 20/2012 “SaRaT-IWSN.”

\section{References}

[1] R. I. Dora, Designul si opimizarea turbinelor eoliene cu ax vertical, de mica putere, implementabile in mediul urban [Ph.D. thesis], Universitatea Transilvania din Brașov, 2014 (Romanian).

[2] A. Grant and N. Kelly, "The development of a ducted wind turbine simulation model," in Proceedings of the 8th International IBPSA Conference, Eindhoven, Netherlands, August 2003.

[3] G. X. Cheng and R. S. Yao, "Study of blades for vertical axis wind turbine," in Proceedings of the International Conference on Solar and Wind Energy Application, pp. 108-114, Beijing, China, August 1985.

[4] M. Ivanoiu, Turbine Eoliene Cu ax Vertical (VAWT). Modele Istorice Ale Transferului Energetic, Editura Universității Transilvania din Brașov, 2013.

[5] D. Le Gourires, Énergie Éolienne, Eyrolles, Paris, France, 1980.

[6] J.-L. Menet, L.-C. Valdès, and B. Ménart, "A comparative calculation of the wind turbines capacities on the basis of the L$\sigma$ criterion," Renewable Energy, vol. 22, no. 4, pp. 491-506, 2000.

[7] G. Pechlivanoglou, Passive and active flow control solutions for wind turbine blades [Ph.D. thesis], Technical University of Berlin, Berlin, Germany, 2013.

[8] I. H. Abbot and A. Von Doenhoff, Theory of Wing Sections: Including a Summary of Airfoil Data, General Publishing Company, Toronto, Canada, 1959. 
[9] G. Bragg and W. Schmidt, "Performance matching and optimization of wind powered water pumping systems," Energy Conversion, vol. 19, no. 1, pp. 33-39, 1979.

[10] W. Bucher, "Performance report of a wind-electric pumping systems," World Energy Congress, vol. 3, pp. 1584-1588, 1990.

[11] J. D. Burton and M. Hijazin, "Lift rod load reduction for wind driven pumps," in Proceedings of the 2nd World Renewable Energy Congress, vol. 3, pp. 1256-1533, Reading, UK, September 1992.

[12] J. D. Burton, "The mechanical coupling of wind turbines to low lift rotodynamic water pumps," Solar and Wind Technology, vol. 5, no. 3, pp. 207-214, 1988.

[13] G. H. Deliu, E. Secara, and M. Macovei, "Regimul aerodinamic al palelor de turbină eoliană cu ax vertical," Buletinul Universităţii Petrol-Gaze Ploieşti, vol. 51, no. 1, pp. 335-338, 1999.

[14] G. H. Deliu, S. Vlase, and M. Deliu, "A study and an optimization of a plane mechanism used in industrial applications," in Proceedings of the International Conference on Adaptive Modelling \& Simulation (ADMOS '03), Book of Abstracts, p. 152, Goteborg, Sweden, 2003.

[15] G. H. Deliu and S. Vlase, "Lanț cinematic închis prin inerție," in Annals of the University of Oradea, pp. 169-175, IMT Oradea, 2005.

[16] M. Deliu and G. H. Deliu, "A simple method to estimate the wind potential of a region," Recent, vol. 8, no. 2, article 20, pp. 91-96, 2007.

[17] M. L. Scutaru, G. H. Deliu, and D. L. Motoc, "Inertia driven reduced DOE mechanism for aeolian pumps," in Proceedings of the 23rd International Congress of Theoretical and Applied Mechanics (ICTAM '12), Beijing, China, August 2012.

[18] M. L. Scutaru, Contributions to the dynamic analysis of transmissions used in small wind turbines [Ph.D. thesis], Transilvania University of Brașov, Brașov, Romania, 2014.

[19] M. L. Scutaru, Mecanica-Cinematica, Teorie şi Aplicaţii, Universității Transilvania din Brașov, 2013.

[20] V. Vălcovici, Șt. Bălan, and R. Voinea, Theoretical Mechanics, Editura Tehnică, București, Romania, 1963.

[21] S. Vlase, "Elimination of lagrangian multipliers," Mechanics Research Communications, vol. 14, no. 1, pp. 17-22, 1987.

[22] S. Vlase, "Method of eliminating lagrangian multipliers from the equation of motion of interconnected mechanical system," Journal of Applied Mechanics, vol. 54, no. 1, pp. 235-237, 1987.

[23] S. Vlase, "Dynamical response of a multibody system with flexible elements with a general three-dimensional motion," Romanian Reports of Physics, vol. 57, no. 3-4, pp. 676-693, 2012.

[24] S. Vlase, P. P. Teodorescu, C. Itu, and M. L. Scutaru, "Elastodynamics of a solid with a general 'RIGID' motion using fem model. part II. analysis of a double cardan joint," Romanian Journal of Physics, vol. 58, no. 7-8, pp. 882-892, 2013.

[25] S. Vlase and P. P. Teodorescu, "Elasto-dynamics of a solid with a general 'rigid' motion using fem model. Part I. Theoretical approach," Romanian Journal of Physics, vol. 58, no. 7-8, pp. 872881, 2013.

[26] S. Vlase, C. Danasel, M. L. Scutaru, and M. Mihalcica, "Finite Element Analysis of a two-dimensional linear elastic system with a plane 'rigide motion," Romanian Journal of Physics, vol. 59, no. 5-6, pp. 476-487, 2014.

[27] S. Vlase, "Eigenvalues and eigenmodes of an inclined homogeneous truss in a rotational field," Romanian Journal of Physics, vol. 59, no. 7-8, pp. 699-714, 2014.
[28] M. L. Scutaru and S. Vlase, "Some properties of motion equations describing the nonlinear dynamical response of a multibody system with flexible elements," Journal of Applied Mathematics, vol. 2012, Article ID 628503, 12 pages, 2012.

[29] AOS Imaging Studio Light Manual Version 2.5.2, 2007. 


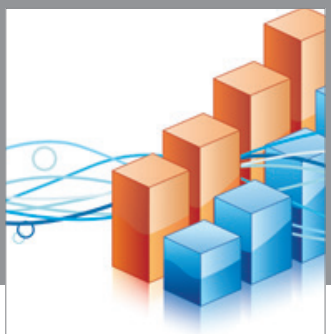

Advances in

Operations Research

vatem alat4

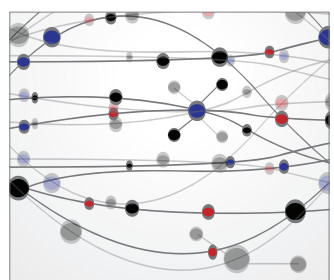

\section{The Scientific} World Journal
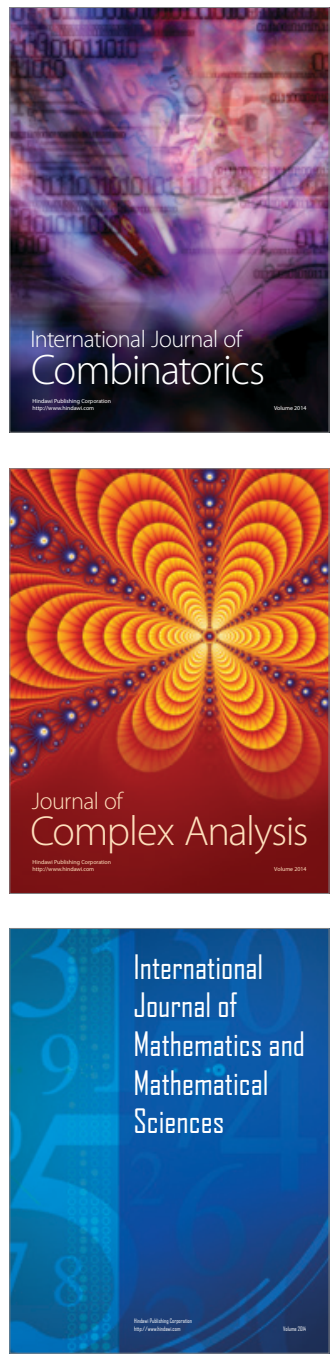
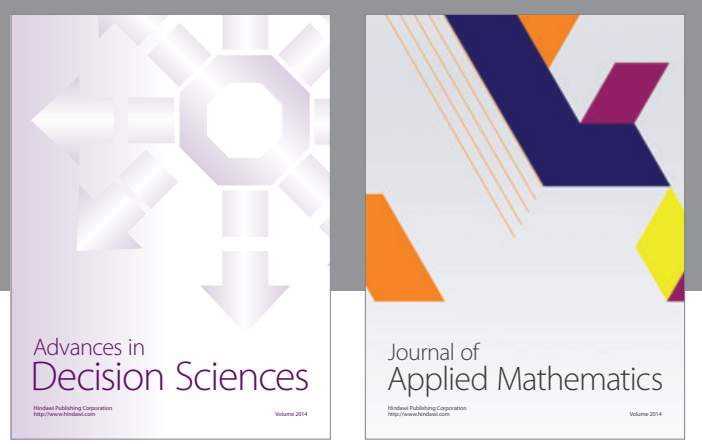

Algebra

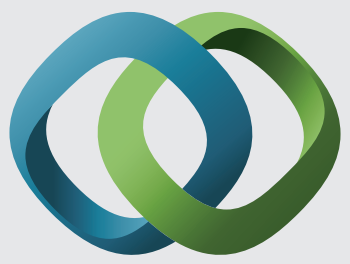

\section{Hindawi}

Submit your manuscripts at

http://www.hindawi.com
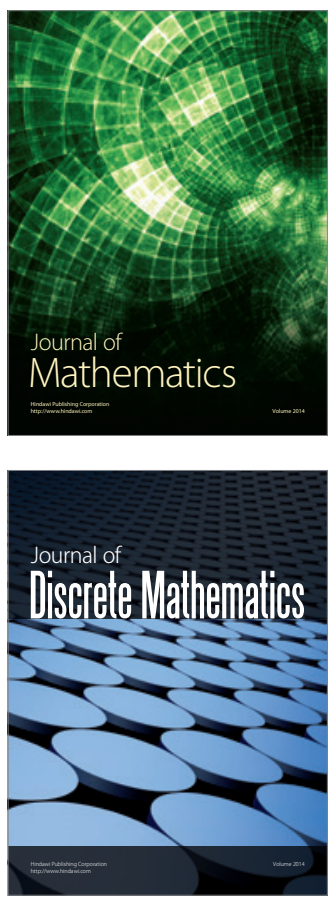

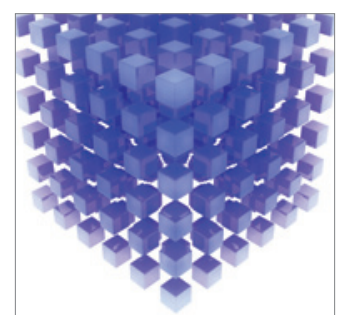

Mathematical Problems in Engineering
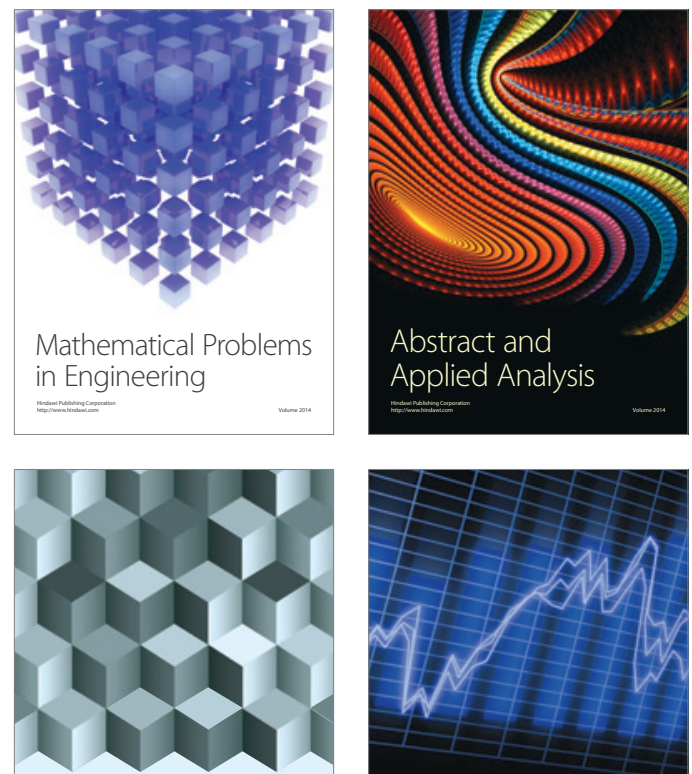

Journal of

Function Spaces

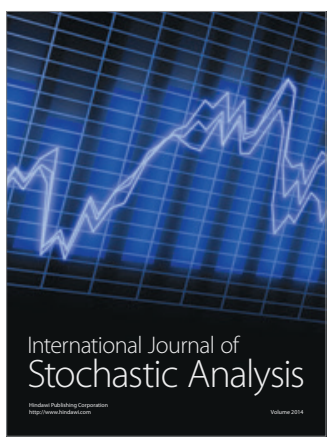

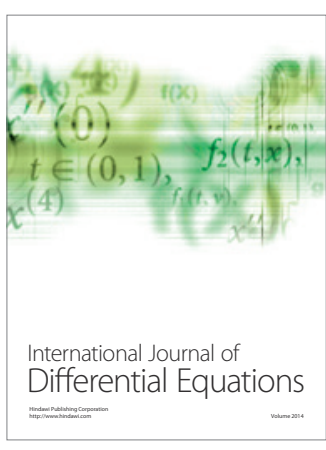
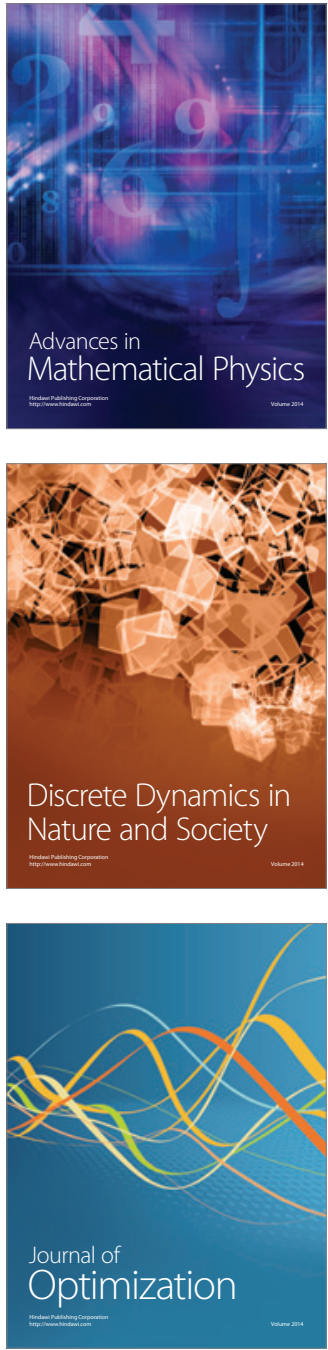